Poland

\title{
FORMULACITY IN ESP TEACHING: A CASE OF DOING A BALANCING ACT BETWEEN FORM AND MEANING
}

\begin{abstract}
Grammar teaching has never belonged to mainstream ESP teaching/learning practices. However, this apparent lack of concern with grammar in ESP materials runs counter to both subjective and objective needs of ESP learners. The first part of the paper presents students' views on deficiencies of coursebooks for teaching English for Medical Purposes (EMP) as well as author's reflective thinking on the needs of medical undergraduates of vocational schools in Poland. It is suggested that some of the deficiencies of the materials might be remedied and the students' needs better taken care of if explicit teaching of formulaic language is introduced into ESP classroom environment. It is hypothesized that explicit teaching of formulaic language may stimulate grammar development in the long term and foster communicative competence of ESP learners in the short term. Therefore, the second part of the paper proposes pedagogically relavant classification of medical formulaic sequences motivated by the lexicogrammatical features of Medical English. The third part of the paper shows in what way the proposed classification of formulaic sequences might help teachers of medical English design tasks that are conducive to the development of formulaic competence of students of English for Medical Purposes.

Keywords: formulaic sequences, crosscultural formulae, culture-specific formulae, conversational formulae, subject-specific formulae, ESP, English for Medical Purposes (EMP).
\end{abstract}

\section{Part I. A need for more grammar and vocabulary teaching in ESP contexts}

It seems fair to claim that grammar teaching does not feature high on the agenda of ESP practioners in vocational schools mainly due to demands of communicative teaching, time pressure and curricular learning outcomes. However, a vast majority of students who enter higher vocational schools represent shaky B1 level of linquistic proficiency, especially if one takes into 
consideration their productive skills. A multiplicity of placement tests as well open-ended tasks set for medical undergraduates by the author of the paper are a case in point. Medical undergraduates of higher vocational schools are exposed to the syllabus which requires of them to possess the knowledge of English at B2 level, whereas lecturers of English are faced with the daunting task of balancing students' learning needs against institutional expectations. It seems that exposure to authentic stretches of formulaic language is the most efficient way to stimulate students' language development and meet the curricular learning outcomes.

Another evidence for the fact that insufficient emphasis is being placed on grammar development in ESP environments is provided by students' views on the content of the coursebooks. In May 2014 fifty-four students of Nursing Faculty of a state higher vocational school in Poland completed a pen-and-paper coursebook evaluation questionnaire drawn up by the author of the paper. Thirty-nine students evaluated Nursing 1 written by Tony Grice and published by Oxford University Press and 14 students evaluated the coursebook entitled Nursing written by Virgina Evans and Kori Salcido, published by Express Publishing. The fomer coursebook does not clarify its CEFRF (Common European Framework of Reference for Languages) level but it may be said to represent B1 level, whereas the latter one consists of three parts ranging from A1 to B1. The questionnaire was completed after three academic terms of working with the coursebooks (90 hours) as the leading teaching resource, i.e. after covering three fourths of the coursebook material. The students were given the opportunity to address the deficiencies of the coursebook in two points given below:

Table 1

An extract from the coursebook evaluation questionnaire: author's own elaboration

\begin{tabular}{|l|l|}
\hline XII. There are not enough exercises that & Circle the correct option or options \\
\hline A - develop listening skills & B - develop speaking skills \\
\hline C - develop reading skills & D - develop writing skills \\
\hline E - develop grammar & F - revise grammar and vocabulary \\
\hline G - develop translation skills & H - develop ... \\
\hline XIII. I would improve the coursebook by & Circle the correct option or options \\
\hline A. by adding exercises that develop self-study skills \\
\hline B. by adding glossary in Polish \\
\hline C. by adding more pronounciation exercises \\
\hline D. by adding ... \\
\hline E. by removing .... \\
\hline F. ... \\
\hline
\end{tabular}


The May 2014 questionnaire revealed that the two ESP coursebooks for nurses laid insufficient emphasis on the development of grammar $(53 \%$ and $57 \%$ respectively) and the revision of the new material (41\% and $42 \%$ respectively). It was also interesting to note that a considerable number of students using 'Nursing' by Evans and Salcido wanted to have translation tasks in their coursebook (42\%). All response rates are presented in Table 2 below.

\section{Table 2}

Findings of the 2014 questionnaire on the deficiencies of two EMP coursebooks: author's own elaboration

\begin{tabular}{|l|l|c|c|c|c|}
\hline \multicolumn{2}{|l|}{ The questionnaire question } & \multicolumn{2}{|c|}{ Nursing 1 by Tony Grice } & $\begin{array}{c}\text { Nursing by Virgina Evans } \\
\text { and Kori Salcido }\end{array}$ \\
\cline { 2 - 6 } & $\begin{array}{c}\text { The number of } \\
\text { respondents }\end{array}$ & $\begin{array}{c}\text { The response } \\
\text { rate }\end{array}$ & $\begin{array}{c}\text { The number of } \\
\text { respondents }\end{array}$ & $\begin{array}{c}\text { The response } \\
\text { rate }\end{array}$ \\
\hline XIIA. & $\begin{array}{l}\text { There are not enough exer- } \\
\text { cises that develop listening } \\
\text { skills. }\end{array}$ & 7 & $18 \%$ & 4 & $28 \%$ \\
\hline XIIB. & $\begin{array}{l}\text { There are not enough exer- } \\
\text { cises that develop speaking } \\
\text { skills. }\end{array}$ & 13 & $33 \%$ & 3 & $21 \%$ \\
\hline XIIC. & $\begin{array}{l}\text { There are not enough exer- } \\
\text { cises that develop reading } \\
\text { skills. }\end{array}$ & 2 & $5 \%$ & 1 & $7 \%$ \\
\hline XIID. & $\begin{array}{l}\text { There are not enough exer- } \\
\text { cises that develop writing } \\
\text { skills. }\end{array}$ & 9 & $23 \%$ & 4 & $28 \%$ \\
\hline XIIE. & $\begin{array}{l}\text { There are not enough exer- } \\
\text { cises that develop grammar. }\end{array}$ & 21 & $53 \%$ & 8 & $57 \%$ \\
\hline XIIF. & $\begin{array}{l}\text { There are not enough exer- } \\
\text { cises that revise grammar } \\
\text { and vocabulary. }\end{array}$ & 16 & $41 \%$ & 6 & $42 \%$ \\
\hline XIIG. & $\begin{array}{l}\text { There are not enough exer- } \\
\text { cises that develop transla- } \\
\text { tion skills. }\end{array}$ & 8 & $20 \%$ & 6 & 0 \\
\hline $\begin{array}{l}\text { There are not enough exer- } \\
\text { cises that develop the skill } \\
\text { of remembering words. }\end{array}$ & 1 & $2 \%$ & 0 & \\
\hline
\end{tabular}

The conclusion to be drawn from the analysis of the questionnaire question above is that ESP teachers should be more concerned with the development and revision of grammar and vocabulary, especially if students have not attained B2 level yet. The sole reliance on the coursebooks to take care 


\section{Urszula Gutowska}

of grammar and vocabulary development and revision may be misguided. It seems that students may need more tasks designed with a view to developing their medical formulaic language. It is hypothesized that explicit teaching of formulaic language may stimulate grammar development in the long term and foster communicative competence of ESP learners in the short term.

\section{Part II. Taxonomy and characterization of formulaic language}

Numerous attempts have been made to define the scope of formulacity. A number of taxonomies and listing conventions have been offered to grasp the functions of formulaic language and its morphosyntactic features. Nattinger, Lewis, Schmitt and Wray's taxonomies are a case in point. Identification criteria or characteristics of formulacity have been proposed, inter alia, by Wray (2002), Gozdawa-Gołębiowski (2008). Various classificatory systems have paved the way for the author's classification of subject-specific formulae relevant for ESP purposes. The classification is exemplified by medical formulaic sequences.

According to Wray, formulaic sequence is a 'sequence of continuous or discontinous of words or other meaning elements, which is or appears to be prefabricated: that is, stored or retrieved whole from the memory at the moment of use, rather than being subject to generalization or analysis by the language grammar' (2002: 465).

Formulaic sequences have been divided into variously named categories (e.g. Jones and Durrant, 2008, Lewis, 1993), depending on the researcher's construct of mental lexicon and the purpose of categorization. Obviously, categories may overlap as the same formulaic sequence may belong to more than one grouping depending on the context of use. All the proposed taxonomies demonstrate lower or higher variability within the formulaic string.

Jones and Durrant (2008) propose a classification of formulaic sequences into collocations and colligations such as by the way, pragmatically specialised expressions such as Happy Birthday', idioms and lexicalized sentence stems such as what's $X$ doing, $X$ BE sorry to keep TENSE you waiting'.

Lewis (1993) makes references to Nattinger's (1988) taxonomy, which encompasses six kinds of lexical items: 1) 'polywords such as idioms, euphemisms, slang, two-and three part verbs; 2) 'phrasal constraints', i.e. fixed phrases subject to some variation within the formulaic string; 3) 'deitic locutions' responsible for maintaining smooth conversational exchanges, 4) 'sen- 
tence builders' such as If I $X$, then $I Y, 5)$ 'situational utterances' highly dependent on communicative context; 6) 'verbatim texts', e.g. quotations or proverbs. (Lewis, 1993: 91) Proliferation of categorizations spurred Lewis to break lexical items into two major groups, namely 'collocations, which are message-oriented and institutionalized expressions, which are essentially pragmatic in nature' (Lewis, 1993: 92). To capture the difference between the two it is useful to draw attention to what Lewis terms 'co-text' and 'context' (1993). 'Co-text' refers to co-occuring linguistic items and 'context' is the situational background determing language use. Lewis takes the view that the collocational meaning is triggered when the meaning of a word or phrase is guessed on the basis of textual clues. Thus, it might be said that collocational meanings are activated by reference to 'co-text' (1993), whereas pragmatic meanings entail interpreting the speaker's purpose by reference to both 'co-text' and 'context'.

According to Lewis, words and collocations are associated with the content of what the language user expresses rather than what the language user is doing' (Lewis 1993: 94). His collocational spectrum ranges from 'unique collocations' (e.g. foot the bill) and 'strong collocations' (e.g. rancid butter), which function almost 'as a single item', to 'weak collocations' that make predictable word combinations and 'medium-strength collocations'. In Lewis' view it is the 'medium-strength collocations' that should play a crucial role in developing the learner's mental lexicon. They contain frequently used words that may collocate with a numerous number of other words, an example being words 'hold' and 'conversation'. Consequently, it is of prime importance for language learning/teaching purposes to be able to understand the 'collocational strength' of various word combinations, i.e. the degree to which they function as more or less separable word combinations. (Lewis 2000: 63-4).

Lewis concurs with Sinclair's (1991) view that collocations illustrate 'the idiom principle'. 'The principle of idiom is that a language user has a large number of semi-preconstructed phrases that constitute single choices, even though they might appear to be analysable into segments'. Representatives of idiomatic language, collocations are 'chunks which have some degree of fixedness, and perhaps some degree of non-literalness'. Consequently, compilers of The Oxford Dictionary of Current Idiomatic English differentiate between 'restricted collocations' where one of the elements is used in a literal sense and the other one in a figurative sense and 'open collocations' where each element has a literal sense. What distinguishes collocations from idioms is not only their semantic transparency but also the focus of description. 'Idioms focus mainly on the meaning of the whole, while collo- 


\section{Urszula Gutowska}

cation is concerned with combinations of words which do or do not occur.' (Lewis 2000: 130-132)

Distinguishing various types of formulaic sequences, Wray, in turn, analyzes both sociolinguistic and psycholinguistic causes of formulacity. She views formulaic sequences as either 'devices of social interaction' (Wray, 2000: 14) or 'compensatory devices for memory limitations' (Wray, 2000: 16). It appears that from the sociolinguistic perspective, formulaic sequences are markers of successive verbal communication, whereas psycholingustic perspective evidences the importance of formulaic language for reducing the amount of online processing of linguistic data.

Formulaic language used for the purpose of social interaction makes it possible to manipulate other people and establish individual or group identity. An extensive list of formulae that are indispensable for effective and skillful functioning in the society encompasses, inter alia, commands, requests, politeness markers, bargains (e.g. I'll give you — for), turn-claimers and holders, group chants, institutionalized forms of word, ritual (e.g Our Father, which art in Heaven...), threats (e.g. I wouldn't do that if I were you), quotations, forms of address, hedges. (Wray, 2000: 14)

Three major groups of formulaic sequences are used to offset limited processing capabilities of human short-term memory. The first group is composed of 'standard phrases with or without gaps' or 'standard ideational labels with agreed meaning'. Their aim is to retrieve ready-made units from memory, obviating the need for time-consuming novelty of expression. The purpose of stalling for time is achieved by means of 'standard phrases with simple meanings (e.g. one way or another), 'fillers' (e.g. if you like), 'turn-holders' (e.g. and let me just say), 'discourse-shape markers' (e.g. Firstly... Secondly..) and 'repetitions of preceding input'. The last group of formulaic sequences comprises mnemonics, 'lengthy texts required to be learnt' and 'rehearsal', which are instrumental in manipulating information. (Wray, 2000: 16). As it will be shown below, in the field of English for Medical Purposes 'standard ideational labels with agreed meaning' and mnemonics not only help to organize vast amounts of medical subjectmatter but also facilitate the acquisition and retention of discipline-specific concepts.

Wray (2002) distinguishes four methods for identifying formulaic sequences: intuition, frequency (formulaic sequences occur repetitively in corpuses), structure (formulaic sequences 'do not follow the usual rules of the language) and phonology ('formulae are sequences which are phonologically coherent), noting that none of them is capable of capturing the phenomenon of formulacity in an adequate and unproblematic way. Even, 
the corpus-based accounts may be unreliable if 'the problem of corpus representativeness and variation between speakers' is not tackled. (Jones and Durrant, 2008: 389-390).

According to Gozdawa-Gołębiowski, an expression is formulaic when 'a statistically significant group of native speakers accesses it as a complete whole chunk, without needing to decompose it' (Gozdawa-Gołębiowski, 2008: 82). In educational contexts the following four types of formulas should be noticed or brought attention to:

- 'formulas as bundles of opaque features', i.e. sequences with 'irregular meaning, function or distribution';

- 'formulas as recurrent units', i.e. sequences that frequently occur;

- 'formulas as social tokens', i.e. sequences that communicatively useful and socially important'

- 'formulas as morphosyntactic exemplars', i.e. sequences that are 'instantiations of productive process'. (Gozdawa-Gołębiowski, 2008: 84)

Wray claims that it has long been recognized that morphemes and polymorphemic words may also be examples of formulaic language. (Wray, 2002: 7, 10). Lewis discusses the concept of formulacity under the umbrella term of 'lexical items' (Lewis 1993, 2000). According to Lewis, 'Lexical items are socially sanctioned independent units. Many are words, but many consist of multi-word units.' (Lewis, 1993: 90) In Wray's model of mental lexicon morpheme equivalent unit (MEU) is 'a word or word string, whether incomplete or including gaps for inserted variable items, that is processed like a morpheme, that is, without recourse to any form-meaning matching of any sub-parts it may have.' (2008: 12)

The problem of defining the scope of formulacity does not rest solely on the overlapping categories or fuzzy boundaries between various types of formulaic sequences. Wray also draws attention to individual differences between language users, stating that the difficulty of defining what constitutes formulaic language is compounded by the need to differentiate 'between something that is formulaic 'in the language', so to speak, and something that is formulaic for just a particular individual or group; and also to distinguish between what is formulaic for a given speaker and for a given hearer' (Wray 2008: 11).

Wray's characterization of formulacity may lead to conclusion that language production exhibits both idiosyncratic and standardized features of formulacity. Idiosyncratic formulacity is determined on a case-by-case basis and is dependent on the individual's mental lexicon, whereas the standardized features of formulacity rely on repetitious occurrences of certain lexicogrammatical patterns, as evidenced by the corpus data. All too often 
communication breakdowns and cultural misunderstandings result from idiosyncrasies of human speech and people's inability to communicate in patterns easily recognizable by a given speech community.

According to Thurston language use within a given community is as either 'esoteric or inward-facing) or exoteric (outward-facing)'. Inward-facing communities preserve their own group identity, have their unique modes of behaviour and daily practices and operate within the same environment. Communication of esoteric communities is chracterized by a high level of formulacity and 'other features related to formulacity such as semantic opacity, grammatical irregularity, and phonological and morphological complexity.' (Laycock, 1979, Thurston, 1987, 1989, 1994, in Wray, 2002: 53), whereas exoteric communities relie on linguistic features that are 'logical, transparent, phonologically and morphologically simple, and (as a result) learnable by adult incomers' (Thurston, 1989; Trudgill, 1989, 2002, in Wray, 2002: 54).

It is beyond doubt that professional communities feature esoteric types of communication because they have their own formulaic language to describe subject - specific or field-specific concepts and constructs. It is argued below that subject-specific formulae may be divided into two major groups depending on their links with local culture.

Crosscultural formulae are individual morphemes, either bound or free, polymorphemic words or multi-word items. They are semantically transparent as their meanings can be either easily inferred on account of crosslinguistic similarities, cross-border applications and the universality of the concepts they refer to. This type of formulae may be loan words or internationally recognized technical linguistic terms.

Culture-specific formulae are either individual morphemes or multiword items. They are steeped in the culture of the person who produces them. A carrier of culture-specific content, they describe job titles, legal concepts, the organization and workings of educational or administrative systems in a given field of study. In English for Medical Purposes they represent medicolegal concepts practically non-existent in Polish medical healthcare or Polish legal system. Examples of crosscultural and culturespecific formulae are given in Table 3 below.

In analyzing formulacity in English for Specific Purposes it seems useful to draw on the distinction between content-obligatory and contentcompatible language operating in the realm of Content and Language Integrated Learning. Making reference to this distinction is well-justified as ESP may be claimed to represent soft CLIL. Soft CIIL is 'language-led', i.e. curricular topics are taught as part of language course. (Bantley 2010: 6). Harmer explains that content-obligatory language are subject-specific words, phrases 
Table 3

Examples of formulaic sequences to illustrate the proposed taxonomy of subject-specific formulae: author's own elaboration

\begin{tabular}{|c|c|}
\hline $\begin{array}{l}\text { Crosscultural formulae across a variety } \\
\text { of semantic fields in medicine }\end{array}$ & $\begin{array}{l}\text { Culture-specific formulae across a variety } \\
\text { of semantic fields in medicine }\end{array}$ \\
\hline $\begin{array}{l}\text { hepatic } \\
\text { its transparency for Polish learner arises } \\
\text { mainly from mental associations with names } \\
\text { of medicines to treat liver disorders } \\
\end{array}$ & $\begin{array}{l}\text { Nurse Practioner (NP) } \\
\text { the term is not easy to translate because } \\
\text { this job title does not have its equivalent in } \\
\text { Polish legal system. }\end{array}$ \\
\hline $\begin{array}{l}\text { bradycardia } \\
\text { it is a phonologically transparent term for } \\
\text { a medical condition whose Polish transliter- } \\
\text { ation is bradykardia }\end{array}$ & $\begin{array}{l}\text { informed consent } \\
\text { it is yet another term which does not trans- } \\
\text { late well; the meaning of the phrase in- } \\
\text { formed in other co-texts and contexts might } \\
\text { be invoked. }\end{array}$ \\
\hline $\begin{array}{l}\text { Sellick maneuver } \\
\text { It is another phonologically transparent } \\
\text { term for a rescue technique. It translates } \\
\text { as 'ręoczyn Sellika'. }\end{array}$ & \multirow[t]{2}{*}{$\begin{array}{l}\text { advance directives and living wills } \\
\text { legal terms referring to end-of-life treatment } \\
\text { options not available in Polish legal system. }\end{array}$} \\
\hline $\begin{array}{l}\text { foreign body airway obstruction (FBAO) } \\
\text { This multi-word chunk is one of the many } \\
\text { phrases which preserve English abbrevia- } \\
\text { tion in Polish texts, i.e. niedrożność dróg } \\
\text { oddechowych spowodowana przez ciało } \\
\text { obce (FBAO) }\end{array}$ & \\
\hline $\begin{array}{l}\text { BLS } \\
\text { BLS, or basic life support (podstawowe za- } \\
\text { biegi resuscytacyjne) is a household name } \\
\text { for life-saving procedures provided without } \\
\text { the use of medication. It is another example } \\
\text { of English abbreviation which accompanies } \\
\text { Polish translation of the term. English ab- } \\
\text { breviation 'BLS' is common in both spoken } \\
\text { and written modes of medical communica- } \\
\text { tion in Polish. In Polish this abbreviation } \\
\text { is pronounced in accordance with rules of } \\
\text { Polish language. However, some English ab- } \\
\text { breviations and acronyms (e.g. AIDS for } \\
\text { acquired immunodeficiency syndrome) in } \\
\text { Polish are pronounced in English-like way. }\end{array}$ & $\begin{array}{l}\text { Medicare and Medicaid } \\
\text { Medicare (Federal Health Insurance for the } \\
\text { Elderly and the Disabled) covers the elderly, } \\
\text { disabled or seriously ill at the state level, } \\
\text { whereas Medicaid (Grants to States for } \\
\text { Medical Assistance Programs) is designed } \\
\text { to address the needs of the indigent popula- } \\
\text { tion. However, it also needs to be pointed } \\
\text { out that the term Medicare has gained } \\
\text { currency in Poland as a business name of } \\
\text { a medical health care centre, thus losing its } \\
\text { link with the American culture. }\end{array}$ \\
\hline $\begin{array}{l}\text { SAMPLE } \\
\text { the memonic is taught in an unchanged } \\
\text { form to Polish students of Paramedic } \\
\text { Science. }\end{array}$ & $\begin{array}{l}\text { SOCRATES } \\
\text { the mnemonic outlines how to conduct pain } \\
\text { interview and is highly culture-specific. The } \\
\text { collected data (semi-structured interviews } \\
\text { with Polish lecturers of occupational sub- } \\
\text { jects) confirm that Poles do not make refer- } \\
\text { ence to this pain assessment framework. }\end{array}$ \\
\hline
\end{tabular}




\begin{tabular}{|l|l|}
\hline $\begin{array}{l}\text { Crosscultural formulae across a variety } \\
\text { of semantic fields in medicine }\end{array}$ & $\begin{array}{l}\text { Culture-specific formulae across a variety } \\
\text { of semantic fields in medicine }\end{array}$ \\
\hline $\begin{array}{l}\text { Crohn's disease } \\
\text { articles in MedlinePlus, online US National } \\
\text { Libery of Medicine, omit Polish surname in } \\
\text { discussions of this disease. }\end{array}$ & $\begin{array}{l}\text { Leśniowski-Crohn's disease } \\
\text { Ileitis terminalis was first described by } \\
\text { the Polish surgeon, Leśniowski. It is ar- } \\
\text { gued that ileitis terminalis is not always } \\
\text { Crohn's disease. Polish medical practioners } \\
\text { and researchers stick to the two-name pre- } \\
\text { modifier. }\end{array}$ \\
\hline $\begin{array}{l}\text { OTC and EXP } \\
\text { mean over the counter and expiration re- } \\
\text { spectively. These two abbreviations com- } \\
\text { monly appear on leaflets or packages of non- } \\
\text { prescription drugs in Poland. }\end{array}$ & \\
\hline
\end{tabular}

and functions essential for comprehending and producing technical concepts, whereas content-compatible language can be used for general English use (Harmer, 2012: 228).

Crosscultural formulae and culture-specific formulae belong to technical, subject-specific formulaic sequences, therefore they constitute contentobligatory language. Crosscultural and culture-specific formulae are pieces of subject-specific idiomatic language that represents varying degrees of fixedness as well as subject-specific abbreviations, acronyms or mnemonic devices. The author's research into the language of English medical coursebooks for students of Emergency Medicine shows that the language abounds in mnemonic devices, ABCD, SAMPLE, RICE, SOCRATES, BOOTS, SLUDGE, SAD PERSONS to mention just a few. In part I above Wray (2000) was quoted to show that mnemonics are a prime example of formulaic language meant to offset memory limitations. In the context of Emergency Medicine mnemonics help students remember what interview questions should be asked or how various types of patients should be managed.

An example of content-compatible language are conversational formulae. They represent a broad spectrum of idiomacity that refers either to subject-specific content by means of imprecise, everyday English accessible to non-professionals or to everyday language for social interaction in occupational settings. In case of English for Medical Purposes conversational formulae may be said to encompass three groups:

- 'pure' and 'figurative' idioms (Lewis, 2000: 130) with some medical word or words such as An apple a day keeps a doctor away or A stitch in time saves nine,

- formulaic strings for social interactions in occupational medical setting, 
as exemplified by Nursing 1 by V. Evans, K. Salcido, e.g. Nurse: How are you holding up today? Patient: Oh, as well as I can, I suppose.

- words and phrases referring to anatomic essentials, medical conditions or therapies, e.g. ease the pain or painkiller.

The last group of conversational formulae corresponds to what Lewis terms sub-technical collocations. He makes an apt remark that they pose most problems to ESP students, being a borderline case between general English and technical English. (Lewis, 2000: 195)

Another interesting aspect of formulacity in English for Specific Purposes is the interface between content-obligatory language, e.g. crosscultural and culture-specific formulae that are subject-specific and contentcompatible language, e.g. conversational formulae. Author's research into the language of medical textbooks reveals that the two types of formulae are at the interface mainly for clarification purposes. Most often this clarification is achieved by means of the word 'or' or by providing subject-specific formulae in brackets. An example list of such formulae is given in Table 4 below.

\section{Table 4}

A sample of medical conversational formulae (the right side) and subjectspecific formulae (the left side): author's own compilation

\begin{tabular}{|l|l|}
\hline \multicolumn{1}{|c|}{$\begin{array}{c}\text { CONVERSATIONAL } \\
\text { FORMULAE }\end{array}$} & \multicolumn{1}{c|}{$\begin{array}{c}\text { SUBJECT-SPECIFIC } \\
\text { FORMULAE }\end{array}$} \\
\hline \multicolumn{2}{|c|}{ A N A T O M Y } \\
\hline spine & vertebral column \\
\hline upper jaw bone & maxilla \\
\hline collarbone & clavicle \\
\hline shoulderblade & scapula \\
\hline rib & costa \\
\hline shinbone & tibia \\
\hline kneecap & patella \\
\hline elbow bone & ulna \\
\hline thigh bone & humerus \\
\hline throat & pharynx \\
\hline voice box & larynx \\
\hline windpipe & trachea \\
\hline chest & thorax \\
\hline bowel & intestine \\
\hline back passage & anus \\
\hline the neck of the womb & cervix \\
\hline related to the nape of the neck & nuchal \\
\hline red blood cells & erythrocytes \\
\hline
\end{tabular}




\begin{tabular}{|l|l|}
\hline \multicolumn{1}{|c|}{$\begin{array}{c}\text { CONVERSATIONAL } \\
\text { FORMULAE }\end{array}$} & $\begin{array}{c}\text { SUBJECT-SPECIFIC } \\
\text { FORMULAE }\end{array}$ \\
\hline \multicolumn{1}{|c|}{ P A T H O P H Y S I O L O G Y } \\
\hline extremely critically \\
\hline narrowed & stenosed \\
\hline narrowing or complete blockage & occlusion \\
\hline slimmers' disease & anorexia \\
\hline broken & fractured \\
\hline fast & rapid \\
\hline tiredness & fatigue \\
\hline sweating & diaphoresis \\
\hline stroke & cerebrovascular accident \\
\hline blood poisoning & septicaemia \\
\hline loss of water & dehydration \\
\hline bleeding & hemorrhage \\
\hline knock knee & genu valgum \\
\hline \multicolumn{2}{|c|}{ T H E R A P I E S } \\
\hline spare part surgery & transplant \\
\hline removal & evacuation \\
\hline follow-up & catamnesis \\
\hline sewed & sutured \\
\hline
\end{tabular}

In Part III there will be proposed tasks to show how the proposed distinction into medical conversational formulae and subject-specific formulae may be exploited in teaching English for Medical Purposes.

Formulae which operate 'as social tokens' (Gozdawa-Gołębiowski, 2008: 82 ) or markers of social identity establish a clear dividing line between an esoeteric community and exoteric community. In the medical settings, the esoteric community is comprised of health care providers and the members of the exoteric community are patients and stakeholders, i.e. people with an vested interest in health care institutions.

It is beyond doubt that if adult foreign learners used formulaic language more frequently, their language comprehension and production would be faster. Speakers would not have to code the message in a novel way and their attentional resources might be directed to the hearers' phonological system and features of interactional setting, whereas hearers would not find it so difficult to decode the massage due to the recognition of familar lexicogrammatical patterns. Thus, it seems fair to claim that in interactional settings the level of formulacity is primarily determined by the hearer's formulaic competence. The wider disparities in formulaic competence between interlocutors, the less formulaic their mutual production is likely to be- 
come, as evidenced by ELF contexts. According to Wray (2002) formulacity decreases when the production adopts written mode and is designed for a complex, outward-facing society. However, it is difficult to agree with this statement when one takes into account professional contexts. Written production uses their own formulae which have their own spoken equivalents as evidenced by Table 4 above.

In conclusion, it should be stated that research into formulaic language grapples with the issue of classifying formulaic language and identifying clear criteria for formulaic status. Following extensive research on formulacity by Wray $(2000,2002,2008)$, the definitional problem seems to be compounded by the fact that formulas may include virtually any word or any type of word combination.

\section{Part III. Pedagogical implications of formulacity}

Teaching formulaic language relevant to students' and curricular needs should be part and parcel of ESP course. According to Basturkmen ESP teaching should meet the following objectives: 'reveal subject specific language use, develop target performance competencies, teach underlying knowledge, develop strategic competence and foster critical awareness'. ESP teaching may be oriented towards one of this objectives but some ESP teachers may give prominence to all or most of them (Baturkmen, 2008: 133). Taking Lewis' view that 'teaching, like language itself, involves knowledge about, but is predominantly procedural knowledge' (1993: 192) it will be shown below how teaching formulaic language fits into ESP teaching objectives.

Lewis makes out a strong case for teaching multi-word chunks within his Observe-Hypothesise-Experiment paradigm. The paradigm recognizes the non-linear nature of acquistion processes. 'Observe: new language must be met and noticed. Hypothesise: means sorting the input on the basis of apparently significant similarities and differences (...) without necessarily being able to describe the categories or storting the process explicitly. Experiment: involves using the language on the basis of the learners' current intergrammar (that is, his or her current best hypothesis), thereby stimulating new input at the appropriate level to provide examples which confirm or contradict some part of the learners' current hypothesis.' (Lewis, 2000: 178)

Instruction that sets out to reveal subject - specific language use is predominaly preoccupied with the analysis of textual patterns and lexical and grammatical and rhetorical features of various text types. Corpus-based 


\section{Urszula Gutowska}

language learning or data-driven learning (DDL) encourages the inductive study of formulaic sequences and their subsequent use. Exposed to authentic stretches of field-specific texts through concordances students learn to notice relevant linguistic data and form hypotheses about the meaning and use of the lexical items.

Basturkmen claims that instruction that aims to develop target performance competencies should focus on formulaic lists for speech acts (2008). It seems that developing 'restricted language repertoire' (Basturkmen, 2008: 136) for highly predictable occupational situations and events is a good starting point for exploring intricacies of occupational knowledge system especially when it comes to ESP courses of longer duration. By way of illustration, the knowledge and understanding of collocational fields of patient assessment according to Glasgow Coma Scale (GCS) is needed to obtain information or describe the patient's level of consciousness in medical occupational contexts. Medical students with a prior of knowledge and understanding of collocational fields related to GCS assessment may take part in a problem-solving task imitating target situation environment. For example, based on case notes they may be asked to evaluate the patient's GCS and decide if the patient is a load and go patient.

Instruction oriented towards teaching ESP students field-specific knowledge and norms and practices of the target situation (Basturkmen, 2006) should pay a close attention to formulae because corpus-based multiple-word chunks are a source of underlying knowledge. English medical textbooks build their students' knowledge around the most frequent type of technical formulae, namely collocations. The following extracts from EMT-Paramedic (2011: pp. 337, 103) are a case in point.

Chapter Question 2: Over time, patients with severe emphysema or chronic bronchitis rely on as the only remaining respiratory drive.
A hypercapnia
B hypocapnia
C hypoxemia
D hypocarbia

Another extract is from Chapter 10 entitled Life-Span Development. The chapter describes, inter alia, physical and mental development of toddlers (12-36 Months). All factual information of the textbook has the format similar to the one given below.

Musculoskeletal system

- Muscle mass increases

- Bone density increases 
It is the teacher's role as the 'provider of input' and 'facilitator of pattern detection' (Thornbury, 2008: 56, 57) to draw students' attention to the fact that multi-word phrases may act as 'knowledge and fluency builders' as exemplified by Task I emphasizing the role of the Noun Phrase.

Task I. Answer the question. What type of accommodation facilities may the geriatric population need?

Answer: (The geriatric population may need) assisted living facilities, nursing homes or other types of sheltered accommodation.

The author takes the view that all formulaic sequences that the teacher introduces should be meaningful for medical undergraduates. Therefore, they should be authentic, i.e. taken from the medical corpus relevant to their field of study without any simplifications. It is the teacher's role as it will be shown below to help students disambiguate the meaning of multiple words chunks such as fluid replacement therapy, medication error or subjectspecific polymorphemic units.

It seems that teaching formulaic sequences as means of building or reinforcing students' subject-specific knowledge should ultimately aim at the development of the ability to recombine chunks in a novel way. Students should be given the opportunity to test their hypotheses about meaning and use of formulaic sequences by experimenting with field-specific concepts in their own way. Experimenting may be more or less controlled.

Task II. Complete the gaps below.

1) Blunt injury to the anterior chest is via the sternum to the heart, causing

2) Hepatitis D is through blood and body fluid exposure, so

Likewise, the rubric of the task itself may also control the way the activity is done. The alternative rubrics of task II above may be worded in the following way:

- How would you complete the two sentences? In what situational contexts might the two sentences be uttered? or

- Is it possible to complete the first gap of each sentene with the same word? Which sentence discusses negative implications of some action? (leading type of the rubic) or 
- Complete the first gap of each sentence with one of the two: obtained, transmitted, transferred. Complete the other gap in the way you deem necessary.

There would be no need to expand the sentence and make it more cognitively demanding, if a full stop was put instead of a comma. Task II above has been inspired by concordancing lines of the author's corpus.

The sentences of task II above relie on sub-technical vocabulary. However, technical and sub-technical vocabulary is insufficient to cover all linguistic dimensions of ESP. Following Douglas (2000) Basturkmen defines strategic competence as 'the means that enables language knowledge and content knowledge to be used in communication'. Developing strategic competence teachers recognize 'the preexisting knowledge base' of the ESP learner (Basturkmen, 2008: 139). As strategic competence refers mainly to communicative strategies ESP learners may need instruction in paraphrasing, making generalization, asking for meaning clarification, etc. Conversational formulae help students produce coherent messages without communication breakdowns.

Culture-specific formulae are instrumental in the development of the last objective ESP teaching, namely critical cultural awarness. Basturkmen claims that 'raising student's critical awareness would involve discussing with students how norms and communicative practices in the target environments become established, encouraging students to critique any negative aspects, and making them aware of ways to try to change or modify the situation so as to position themeselves better in relation to it.' (2008: 141) Intercultural tasks can be designed to activate crosscultural comparisons and develop students critical skills in line with Byram's model of communicative cultural competence. Culture-specific formulae offer a spingboard into analyzing cultural differences and similarites. ESP medical textbooks are usually biased towards presenting a one-sided view of occupational setting, norms and communicative practices. The concept of informed consent is found in commercial EMP textbooks by American authors, the example being Nursing 1 by V. Evans, K. Salcido or Medicine 1 by S. MacCartner. By the same token, EMP textbooks produced in Poland offer a culture-specific formulae describing educational system and career path of medical practitioners in Poland, the example being English for Paramedics by Z. Patoka, I. Okulicz. Dealing with culture-specific formulae calls for explicit instruction because students often lack expert knowledge when it comes to culturerelated topics. Explicit instruction may offset the imbalances of power or unequal treatment of culture-specific formulae inherent in the commercial ESP textbooks. 
Cross-cultural formulae impose a different role on students and teachers. In decoding the meaning and using crosscultural formulae ESP students may act as field experts, activating their schematic knowledge. The teacher acts as a supplier of what Seal terms three Cs. Seal's Three Cs refer to three teaching strategies such as conveying meaning, checking the meaning and consolidating the meaning with reference to the context and personal experience (in Pavičić Takač, V., 2008). Below it will be shown how consolidation of learning material is achieved through contextualized form-and meaningfocused activities (SAMPLE mnemonic) and how meaning is conveyed and checked through decontextualized grammaring tasks.

SAMPLE mnemonic is an example of crosscultural formula which can be incorporated into role-playing tasks. Due to the fact that it is taught by teachers of medical occupational subjects students can act as field experts taking medical history. SAMPLE mnemonic is suitable for practising a whole range of grammatical forms in a meaningul context. The framework makes it incumbent on the ESP student of Paramedic Science to ask the patient (another student) questions about symptoms, allergies, medication, past medical history, last meal and events leading to the illness or injury. While one student practises interviewing skills based on questions starting with Do you... Are you...? (When) did you...?? (How long) Have you...? What happened...? etc., the other student may use field-specific formulaic sequences. The framework may be incorporated into a variety of form-fluency tasks dealing with case studies.

The analysis of constituent parts of formulaic string may trigger interlanguage development. Foreign Body Airway Obstruction (FBAO) is a perfect candidate for grammaring or grammar emergence tasks. Proposed by Thornbury, grammaring tasks involve moving from lexical mode to a more grammatical mode, 'adding grammar to de-grammared, essentially lexicial texts' (Thornbury, 2008: 81). Underlying conditions for grammaring are 'low context dependence', 'high incentive for precision', low pressure', 'high feedback' (Thornbury, 2008: 21). In line with Thornbury' principles of grammar as an emergent phenomenon, Task III proposed below should help students acquire or develop the skill of explanation of unfamiliar words.

Task III. Complete the gaps with missing words.

foreign body airway obstruction $=$ an obstruction airway caused the foreign body

The above grammaring task has been inspired by Thornbury's approach to developing students' linguistic resources. However the importance 
of function words, especially 'the central role of of' has also been recognized by Lewis. (Lewis, 2000: 145)

Grammar emerges if students are encouraged to unpack the meaning of multi-chunks or polymorphemic units by adding relevant grammatical words. As this type of meaningul grammar task does not feature in the ESP textbooks, the teacher should supply a couple of model examples, e.g., thoracotomy = making a cut through the chest wall, thrombus formation $=$ formation of thrombus, ie. blood cut.

Polish students should be made aware that decoding of the formulaic string should start from the last word or last morpheme within the formulaic string. The researcher's analysis of the student's interlanguage shows that their inability to understand and produce the correct two or three - word noun phrase is a source of persistent comprehension and production errors.

In case of polymorphemic words, e.g. osteoarhritis students should be supplied with relevant linguistic context or explicitly made aware of the meaning of individual words and morphemes prior to the task of clarifying the meaning of the whole formula. Therefore, explicit teaching of morphemes of Greek and Latin origin such as -dynia, -emia, -its or myo, hemo- should be an indispensable part of formulaic language teaching because they are subject-specific cross cultural formulae.

It is assumed that the knowledge of the meaning of individual morphemes of an unfamilar formula is likely to stimulate processing of the linguistic information and trigger the inherent analytic resources of the adult learners in accordance with the competing cognitive systems hypothesis. Unlike children, adults can deal with with abstract formal systems and process the data through the the 'Problem Solving Cognitive System' which substitutes the 'the Language Aquistion Device' around puberty (BleyVroman, 1990).

The last example of task concerns the proposed distinction of formulaic sequences into subject-specific formulae and conversational formulae. Students may be given a task that shows how the use of appropriate formulae is instrumental in facilitating exchange between health care professionals representing uneven knowledge status or healthcare professionals and patients.

Task IV. Complete the gaps below. Then practise similar dialogues.

Patient to the Nurse: Will I get any cough medicine soon? I cannot stop coughing.

(Later on) Doctor to the Nurse: Patient in room 203 needs an a_ _. _. _. _ e. Give him Codeine $40 \mathrm{mg}$ PO. 
Nurse to the Patient: Mr Robben, take Furosemide, it is a water pill. It should help you get rid of unwanted water.

(Later on) Nurse to another Nurse: I have just given Mr Robben the d _ . . . . . . that the doctor prescribed.

Students have no problems in identifying the differences between formal and informal register if they are regularly exposed to tasks that help them recognize conversational and subject-specific collocations. Task type $\mathrm{V}$ below has been inspired by Michael Lewis' lexical approach.

Task V. Find the odd one out.

1. water pills cough medicine painkillers diuretics

2. analgesics sleeping pills antiemetics hypnotics

To sum up, students may be given numerous tasks where more or les explicit reference will be made to the division of subject-specific formulaic sequences into cross-cultural and culture-specific formulae or to the division of formulaic sequences into conversational and subject-specific formulae. Needless to say, the pre-taught formulaic sequences may then be incorporated into truly meaningful tasks that imitate target situations.

\section{Conclusion}

The overall aim of the paper is to show a need for a more explicit teaching of formulaic sequences as they may be said to stimulate communicative language teaching and language development. The first part of the paper presents the findings of the coursebook evaluation questionnaire with a view to showing that medical undergraduates are concerned with insufficient amount of grammar teaching and grammar and vocabulary revision exercises in their coursebooks. The author hypothesizes that the focus on formulaic sequences may help students develop their linguistic resources and improve their conversational efficiency. The second part presents taxonomies and criteria for identification of formulaic sequences and proposes author's own classification of formulaic sequences relevant for ESP teaching/learning needs. The third part considers pedagogical implications of the proposed taxonomy, claiming that the focus on formulaic sequences not only helps realize ESP teaching objectives proposed by Basturkmen (2008) but also helps restructure students' interlanguage in line with lexical-to-grammatical orientation of language acquistion propounded by Lewis $(1993,2000)$ and Thornbury (2008). 
Bley-Vroman, R. 1989. 'The logical problem of foreign language learning'. Linguistic Analysis 20: 3-49.

Basturkmen, H. 2008. Ideas and Options in English for Specific Purposes. New Jersey: Laurence Erlbaum Associates, Inc.

Bentley, K. 2010. The TKT Course. CLIL Module. Cambridge: Cambridge University Press.

Conklin, K., Schmitt, N. 2008. 'Formulaic Sequences: Are they processed more quickly than nonformulaic language by native and nonnative speakers?' $A p$ plied Linguistics: 29/1 72/89. Oxford University Press.

Gozdawa-Gołębiowski, R. 2008. Gramar and Formulacity in Foreign Language Teaching. Poznań: Wydawnictwo Naukowe UAM Glottodidactica Vol. XXXIV.

Harmer, J. 2012. Teacher Knowledge. Core Concepts in English Laguage Teaching. Essex: Pearson Education Limited.

Jones, M., Durrant, Ph. 2008. What can a corpus tell us about vocabulary teaching materials? In A. O'Keeffe, M. McCarthy (eds.), The Routledge Handbook of Corpus Linguistics. (387-400) New York: The Taylor \& Francis Group.

Lewis, M. 1993. Lexical Approach. Language Teaching Publications.

Lewis, M. 2000. Teaching Collocation. Further Developments in Lexical Approach. London: LTP Teacher Training.

Pavičić Takač, V. 2008. Vocabulary Learning Strategies and Foreign Language Acquistion. Clevendon: Multilingual Matters.

Sinclair, J. 1991. Corpus, Concordance, Collocation, Oxford University Press.

Thornbury, S. 2008. Uncovering Grammar. Oxford: Macmillan Education.

Wray, A., Perkins, M. 2000. 'The functions of formulaic language: an integrated model'. Language \& Communication Vol. 20 (1): 1-28.

Wray, A. 2002. Formulaic Language and the Lexicon. Cambridge: Cambridge University Press.

Wray, A. 2008. Formulaic Language: Pushing the Boundaries. Oxford University Press. 